\title{
Raspodjela ostataka pesticida između kore i pulpe naranče
}

2IIIIIIIIIIIIIIIIIIIIIIIIIIIIIIIIIIIIIIIIIIIIIIIIIIIIIIIIIIIIIIIIIIIIIIIIIIIIIIIIIIIIIIIIIIIIIIII

1 Ljubica Hrnjkaš

2 Aleksandar Racz

1 Hrvatski zavod za javno zdravstvo, Rockefellerova 7, Zagreb, Hrvatska

2 Zdravstveno veleučilište Zagreb, Mlinarska 38, Zagreb, Hrvatska

\section{Sažetka}

:

Cilj rada bio je dokazati transfer ostataka pesticida $\mathrm{s}$ kore na pulpu ako se dokaže njihova prisutnost na kori naranče. $U$ tu svrhu u radu je analizirano 48 uzoraka naranči iz uvoza i domaćeg porijekla u kojima su analize bile usmjerene na detekciju 88 aktivnih tvari. Rezultati su pokazali da su bile potvrđene četiri aktivne tvari: imazalil, klorpirifos, tiabendazol i bifentrin, pri čemu je transfer aktivnih tvari dokazan na 11 uzoraka te se kretao u rasponu od $20 \%$ do $30 \%$.
Ključne riječi: naranča, transfer, pesticidi, imazalil, klorpirifos, tiabendazol i bifentrin

Datum primitka: 15.11 .2020$.

Datum prihvaćanja: 01.03.2021.

https://doi.org/10.24141/1/7/2/8

Adresa za dopisivanje:

Aleksandar Racz

Zdravstveno veleučilište

E-pošta: aracz@zvu.hr

T: +385914595 722 


\section{Uvod}

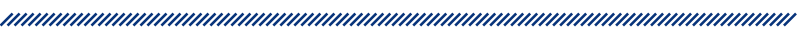

Naranča je suptropska biljka iz porodice Rutaceae koja se uzgaja u regijama s toplom klimom poput Sredozemlja, Južne Afrike i Kalifornije i čiji se plod osim u prehrani upotrebljava i u proizvodnji kozmetike i parfema. ${ }^{1}$ S obzirom na to da u raznim fazama uzgoja i proizvodnje stablo i plod naranče mogu biti tretirani raznim pesticidima, monitoring ostataka pesticida u hrani ima za cilj ustanoviti količinu ostataka pesticida u proizvodima biljnog podrijetla, provjeriti odgovaraju li propisima koji određuju maksimalne razine ostataka (MDK) pesticida i pridržavaju li se proizvođači načela dobre poljoprivredne prakse te tako zaštititi zdravlje potrošača. Nacionalni program praćenja (monitoringa) ostataka pesticida u skladu je sa standardima za monitoring koji se provodi u državama Europske unije.

\section{Cilj rada, materijal i metode}

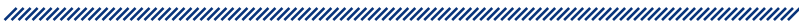

Cilj rada bio je dokazati transfer ostataka pesticida između kore i pulpe naranče ako se dokaže njihova prisutnost na kori.

U tu svrhu tijekom 2011. godine bili su analizirani uzorci naranči, koje je u sklopu službene kontrole izdvojila granična sanitarna inspekcija, u ovlaštenom laboratoriju akreditiranom prema standardu ISO 17025 . $^{2}$ Svi uzorci pripravljeni su u skladu s normom HRN EN 12393:1998. ${ }^{3}$

Ispitni uzorak prvo je bio ekstrahiran s acetonom nakon dodavanja vode u svrhu održavanja omjera acetona i vode $2: 1$. U svrhu razdjeljivanja u homogenizat je dodana smjesa cikloheksana i etilacetata uz zasićenje natrijevim kloridom. Alikvot organske faze sušio se natrijevim sulfatom i koncentrirao pod vakuumom. $U$ dobiveni ostatak dodana je smjesa etilacetata i cikloheksana $(1: 1)$, otopina je filtrirana preko filtra od $0,4 \mu \mathrm{m}$ i pročišćena gel-permeacijskom kromatografijom uz upotrebu polistirenskog gela Bio-beds SX3 i uz eluiranje smjesom cikloheksana i etilacetata. Uzorci su analizirani na masenom spektrometru. Prilikom analize primijenjena je multirezidualna metoda, pri čemu se analit identificirao prema retencijskom vremenu u skladu s retencijskim vremenima analita iz odgovarajuće otopine standarda.

\section{Rezultati}

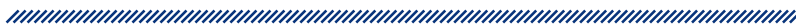

Analizom su u uzorcima detektirane sljedeće aktivne tvari: klorpirifos, imazalil, tiabendazol i bifentrin.

\begin{tabular}{|c|c|}
\hline Aktivna tvar & MDK mg/kg \\
\hline Imazalil & 5 \\
\hline Tiabendazol & 5 \\
\hline Klorpirifos & 0,3 \\
\hline Bifentrin & 0,1 \\
\hline
\end{tabular}

\begin{tabular}{|c|c|}
\hline \multicolumn{2}{|c|}{$\begin{array}{c}\text { Tablica 2. Granica kvantifikacije za } \\
\text { detektirane aktivne tvari u uzorcima } \\
\text { naranče }\end{array}$} \\
\hline Aktivna tvar & LOQ mg/kg \\
\hline Imazalil & 0,02 \\
\hline Tiabendazol & 0,05 \\
\hline Klorpirifos & 0,01 \\
\hline Bifentrin & 0,01 \\
\hline
\end{tabular}




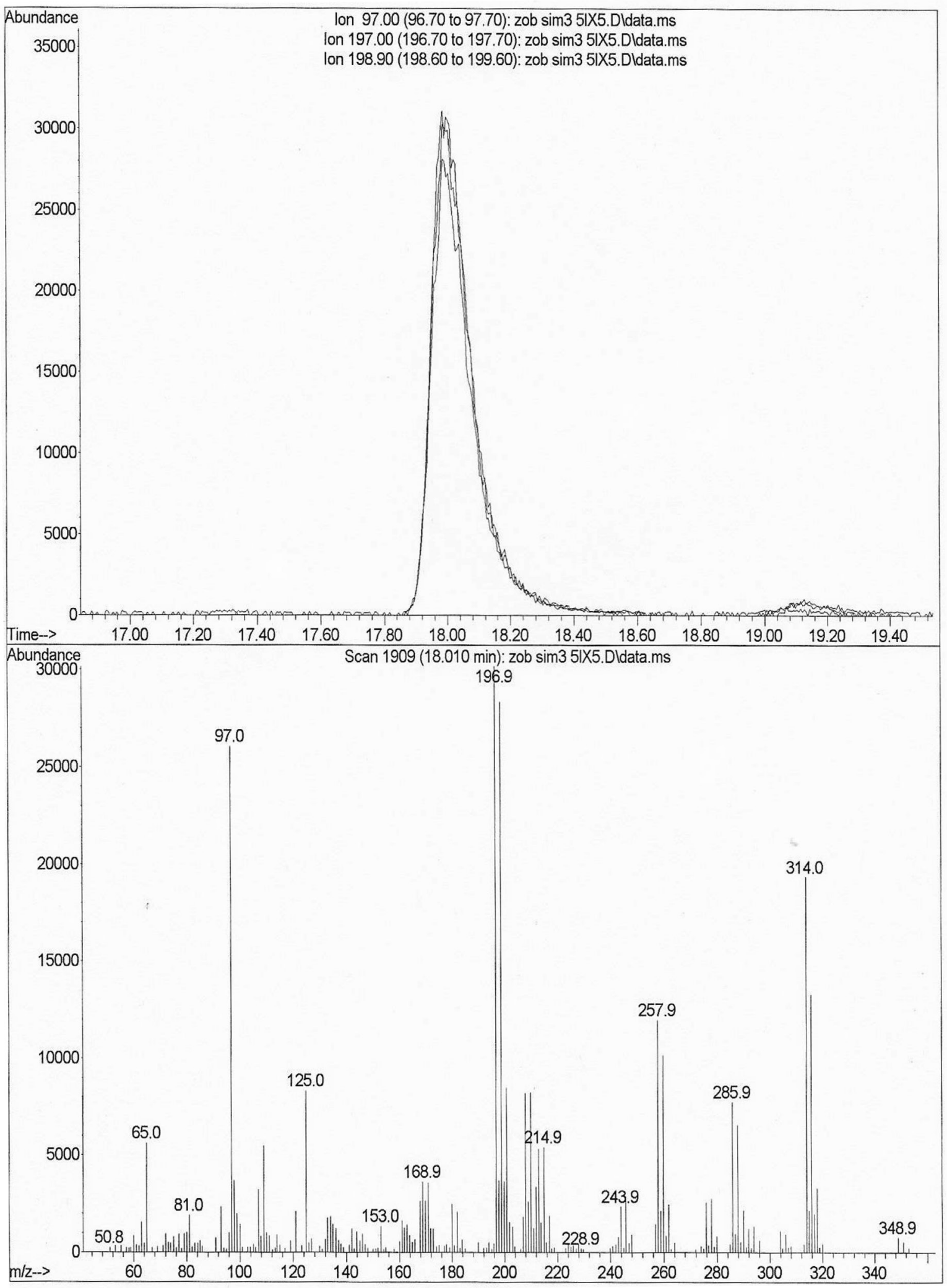

Slika 1. Kromatogram iona klorpirifosa 


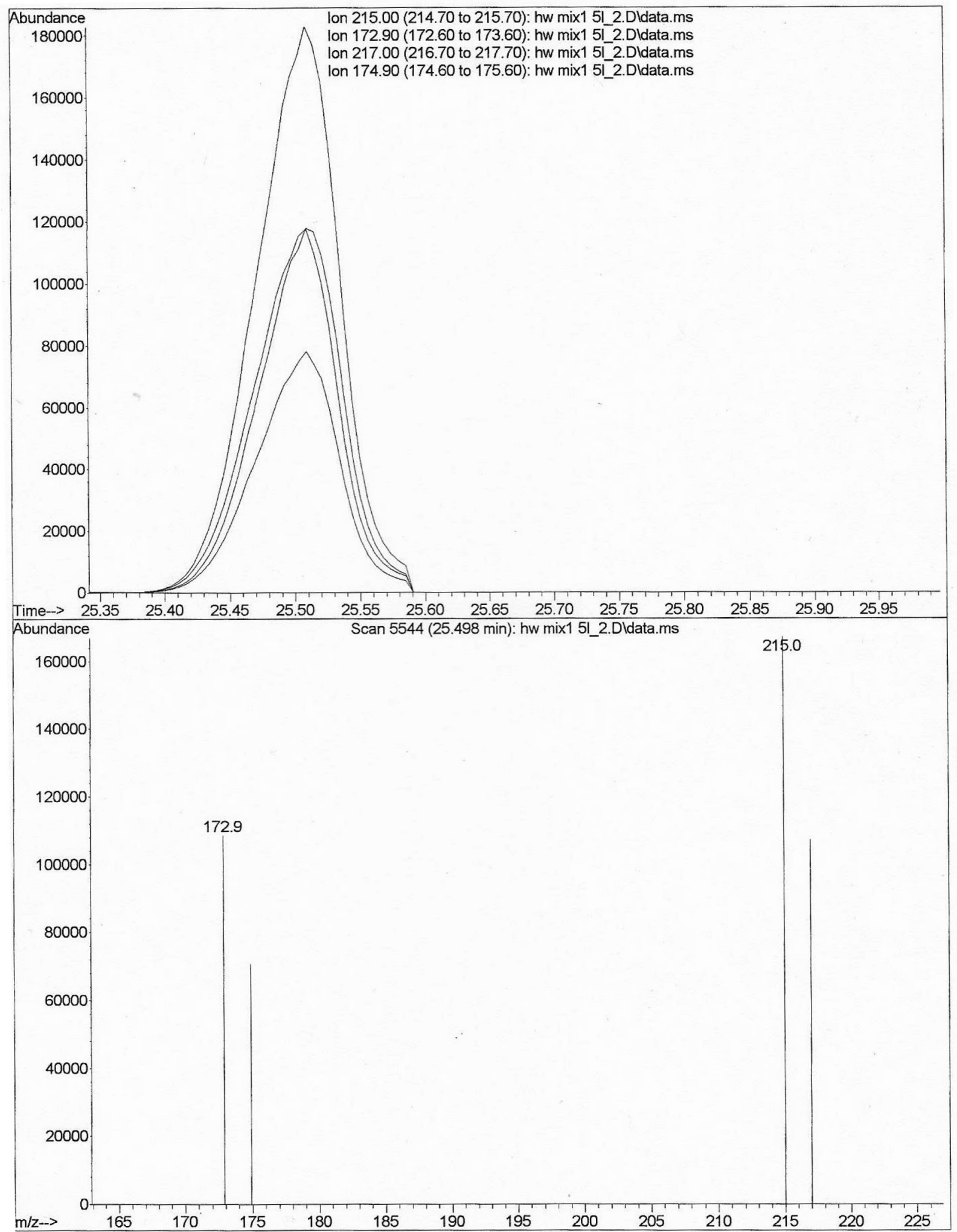




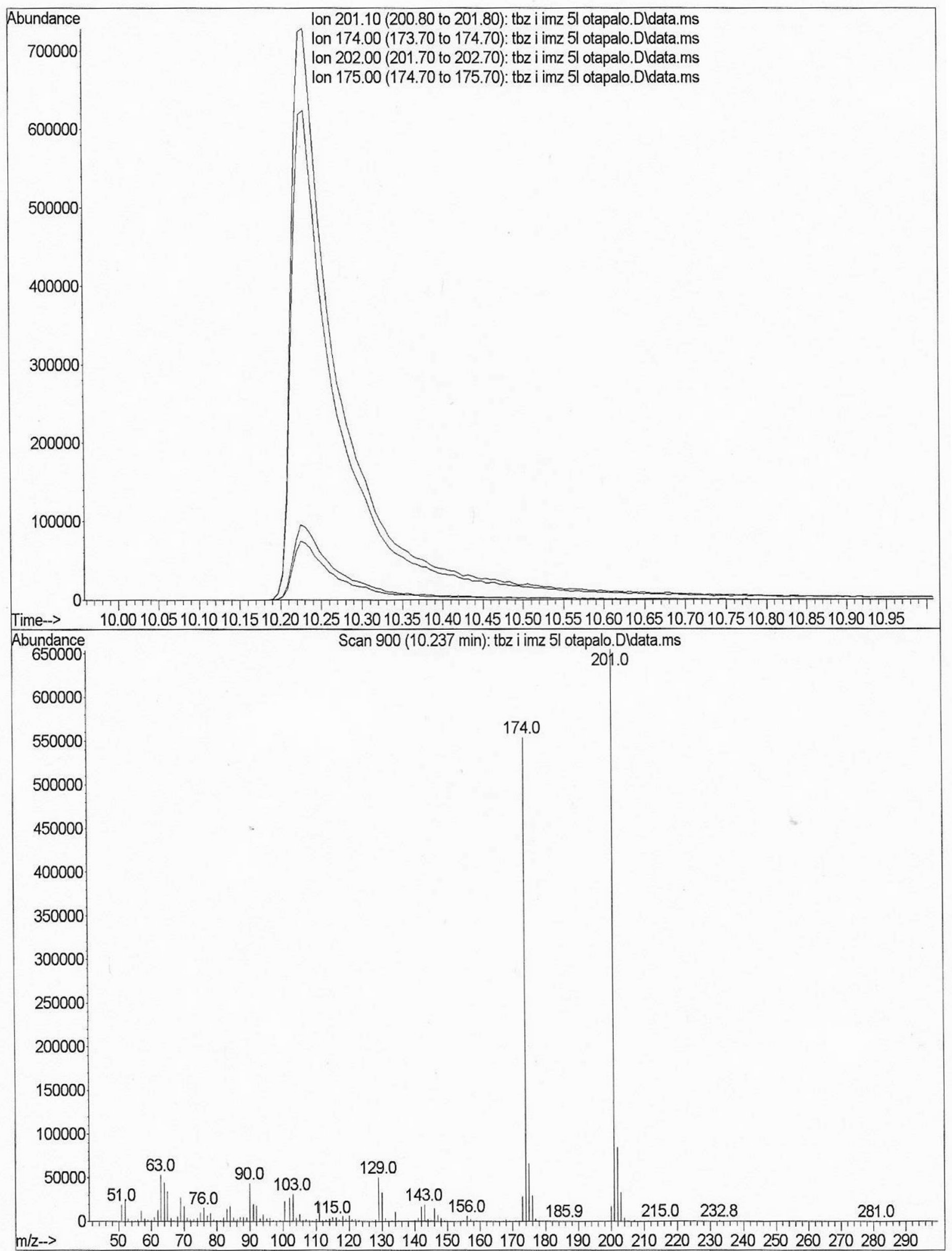

Slika 3. Kromatogram iona tiabendazola 


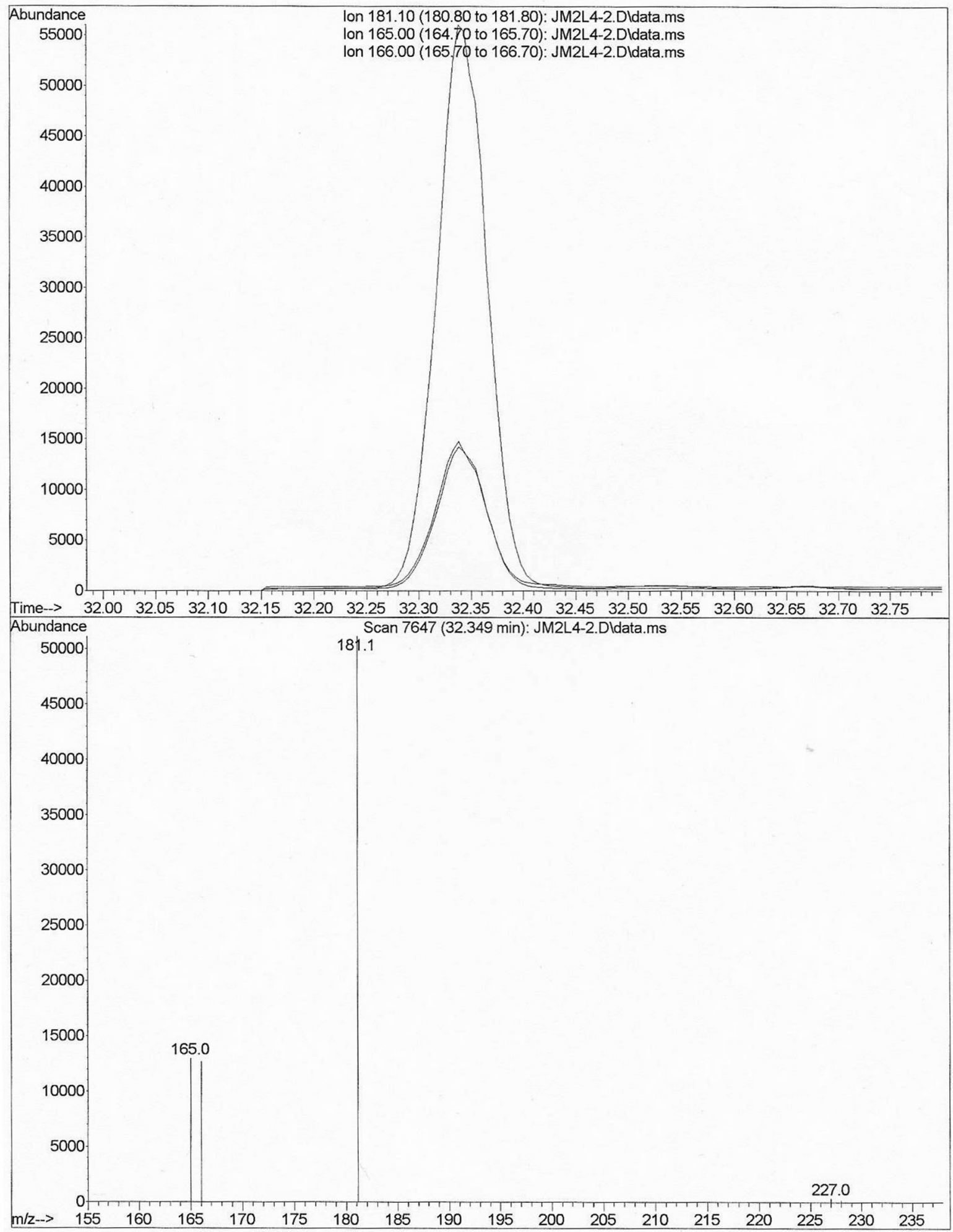




\begin{tabular}{|c|c|c|}
\hline Uzorak & Zemlja podrijetla & Aktivna tvar \\
\hline 1 & Španjolska & imazalil \\
\hline 2 & Španjolska & klorpirifos, imazalil \\
\hline 3 & Španjolska & $\begin{array}{c}\text { klorpirifos, imazalil, } \\
\text { bifentrin }\end{array}$ \\
\hline 4 & Egipat & bifentrin \\
\hline 5 & Španjolska & klorpirifos, imazalil \\
\hline 6 & Španjolska & klorpirifos, imazalil \\
\hline 7 & Grčka & imazalil \\
\hline 8 & Španjolska & tiabendazol \\
\hline 9 & Grčka & klorpirifos \\
\hline 10 & Grčka & $<$ LOD \\
\hline 11 & Grčka & $<$ LOD \\
\hline 12 & Španjolska & bifentrin, klorpirifos \\
\hline 13 & Španjolska & $<\mathrm{LOD}$ \\
\hline 14 & Španjolska & $<$ LOD \\
\hline 15 & Španjolska & $<$ LOD \\
\hline 16 & Kostarika & tiabendazol \\
\hline 17 & JAR & tiabendazol, imazalil \\
\hline 18 & JAR & tiabendazol, imazalil \\
\hline 19 & Hrvatska & $<$ LOD \\
\hline 20 & JAR & imazalil \\
\hline 21 & Egipat & imazalil \\
\hline 22 & Španjolska & $<$ LOD \\
\hline 23 & Hrvatska & tiabendazol \\
\hline 24 & Hrvatska & $<$ LOD \\
\hline 25 & Hrvatska & $<$ LOD \\
\hline 26 & Turska & $<$ LOD \\
\hline 27 & Hrvatska & $<$ LOD \\
\hline 28 & Turska & $<$ LOD \\
\hline 29 & Hrvatska & $<$ LOD \\
\hline 30 & JAR & $<$ LOD \\
\hline 31 & Španjolska & imazalil \\
\hline 32 & Hrvatska & $<$ LOD \\
\hline 33 & Hrvatska & tiabendazol, imazalil \\
\hline 34 & Hrvatska & $<$ LOD \\
\hline 35 & Turska & klorpirifos \\
\hline 36 & Turska & klorpirifos \\
\hline 37 & Hrvatska & klorpirifos, imazalil \\
\hline 38 & Hrvatska & imazalil \\
\hline 39 & Turska & klorpirifos \\
\hline 40 & JAR & imazalil \\
\hline 41 & Španjolska & klorpirifos \\
\hline 42 & Argentina & imazalil \\
\hline 43 & JAR & imazalil \\
\hline 44 & Hrvatska & $<$ LOD \\
\hline 45 & Hrvatska & $<$ LOD \\
\hline 46 & Španjolska & $<$ LOD \\
\hline 47 & Hrvatska & $<$ LOD \\
\hline 48 & Turska & $<$ LOD \\
\hline
\end{tabular}

\begin{tabular}{|c|c|c|c|}
\hline \multicolumn{4}{|c|}{ IMAZALIL } \\
\hline Uzorak & Kora & Pulpa & $\begin{array}{c}\text { Transfer } \\
\text { aktivne tvari }\end{array}$ \\
\hline 1 & $1,71 \mathrm{mg} / \mathrm{kg}$ & $0,49 \mathrm{mg} / \mathrm{kg}$ & $29 \%$ \\
\hline 2 & $2,52 \mathrm{mg} / \mathrm{kg}$ & $0,63 \mathrm{mg} / \mathrm{kg}$ & $25 \%$ \\
\hline 3 & $3,48 \mathrm{mg} / \mathrm{kg}$ & $1,04 \mathrm{mg} / \mathrm{kg}$ & $30 \%$ \\
\hline 4 & $1,26 \mathrm{mg} / \mathrm{kg}$ & $0,27 \mathrm{mg} / \mathrm{kg}$ & $22 \%$ \\
\hline 5 & $1,09 \mathrm{mg} / \mathrm{kg}$ & $0,21 \mathrm{mg} / \mathrm{kg}$ & $26 \%$ \\
\hline 6 & $0,49 \mathrm{mg} / \mathrm{kg}$ & $<$ LOQ & I \\
\hline 7 & $0,38 \mathrm{mg} / \mathrm{kg}$ & $<\mathrm{LOQ}$ & I \\
\hline 8 & $0,46 \mathrm{mg} / \mathrm{kg}$ & $<$ LOQ & I \\
\hline 9 & $0,76 \mathrm{mg} / \mathrm{kg}$ & $0,18 \mathrm{mg} / \mathrm{kg}$ & $24 \%$ \\
\hline 10 & $0,88 \mathrm{mg} / \mathrm{kg}$ & $0,19 \mathrm{mg} / \mathrm{kg}$ & $22 \%$ \\
\hline 11 & $2,41 \mathrm{mg} / \mathrm{kg}$ & $0,67 \mathrm{mg} / \mathrm{kg}$ & $28 \%$ \\
\hline 12 & $0,35 \mathrm{mg} / \mathrm{kg}$ & $<\mathrm{LOQ}$ & 1 \\
\hline 13 & $0,37 \mathrm{mg} / \mathrm{kg}$ & $<$ LOQ & I \\
\hline
\end{tabular}

\begin{tabular}{|c|c|c|c|}
\hline \multicolumn{4}{|c|}{ TIABENDAZOL } \\
\hline Uzorak & Kora & Pulpa & $\begin{array}{c}\text { Transfer } \\
\text { aktivne tvari }\end{array}$ \\
\hline 1 & $1,42 \mathrm{mg} / \mathrm{kg}$ & $0,34 \mathrm{mg} / \mathrm{kg}$ & $24 \%$ \\
\hline 2 & $1,00 \mathrm{mg} / \mathrm{kg}$ & $0,21 \mathrm{mg} / \mathrm{kg}$ & $21 \%$ \\
\hline 3 & $0,77 \mathrm{mg} / \mathrm{kg}$ & $0,19 \mathrm{mg} / \mathrm{kg}$ & $25 \%$ \\
\hline 4 & $0,37 \mathrm{mg} / \mathrm{kg}$ & $<\mathrm{LOQ}$ & l \\
\hline
\end{tabular}

\begin{tabular}{|c|c|c|c|}
\hline \multicolumn{3}{|c|}{$\begin{array}{c}\text { Tablica 6. Prisutnost aktivne tvari } \\
\text { klorpirifosa te njezin transfer s kore na } \\
\text { pulpu izražen u postotku }\end{array}$} \\
\hline \multicolumn{4}{|c|}{ KLORPIRIFOS } \\
\hline Uzorak & Kora & Pulpa & $\begin{array}{c}\text { Transfer } \\
\text { aktivne tvari }\end{array}$ \\
\hline 1 & $0,09 \mathrm{mg} / \mathrm{kg}$ & $<\mathrm{LOQ}$ & $/$ \\
\hline 2 & $0,07 \mathrm{mg} / \mathrm{kg}$ & $<\mathrm{LOQ}$ & $/$ \\
\hline 3 & $0,03 \mathrm{mg} / \mathrm{kg}$ & $<\mathrm{LOQ}$ & $/$ \\
\hline 4 & $0,04 \mathrm{mg} / \mathrm{kg}$ & $<\mathrm{LOQ}$ & $/$ \\
\hline 5 & $0,07 \mathrm{mg} / \mathrm{kg}$ & $<\mathrm{LOQ}$ & $/$ \\
\hline 6 & $0,08 \mathrm{mg} / \mathrm{kg}$ & $<\mathrm{LOQ}$ & $/$ \\
\hline 7 & $0,03 \mathrm{mg} / \mathrm{kg}$ & $<\mathrm{LOQ}$ & $/$ \\
\hline 8 & $0,03 \mathrm{mg} / \mathrm{kg}$ & $<\mathrm{LOQ}$ & $/$ \\
\hline 9 & $0,01 \mathrm{mg} / \mathrm{kg}$ & $<\mathrm{LOQ}$ & $/$ \\
\hline 10 & $0,02 \mathrm{mg} / \mathrm{kg}$ & $<\mathrm{LOQ}$ & $/$ \\
\hline 11 & $0,05 \mathrm{mg} / \mathrm{kg}$ & $<\mathrm{LOQ}$ & $/$ \\
\hline
\end{tabular}




\section{ZEMLJE PODRIJETLA UZORAKA}

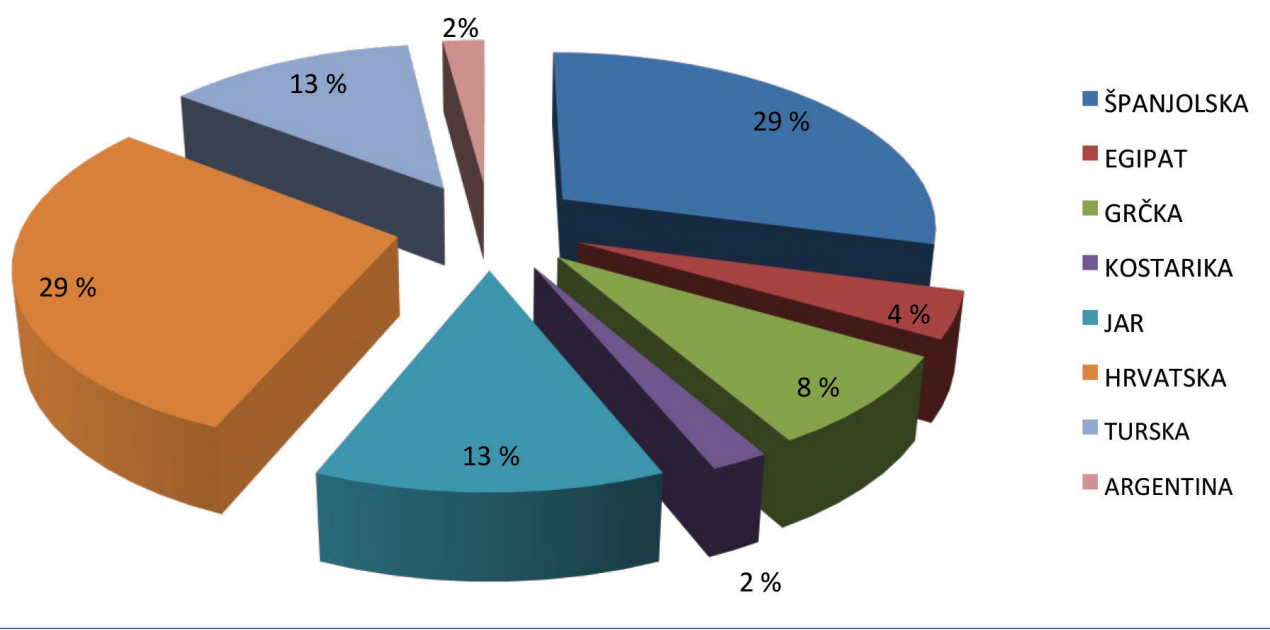

Grafikon 1. Zemlja podrijetla analiziranih uzoraka izraženih u postocima

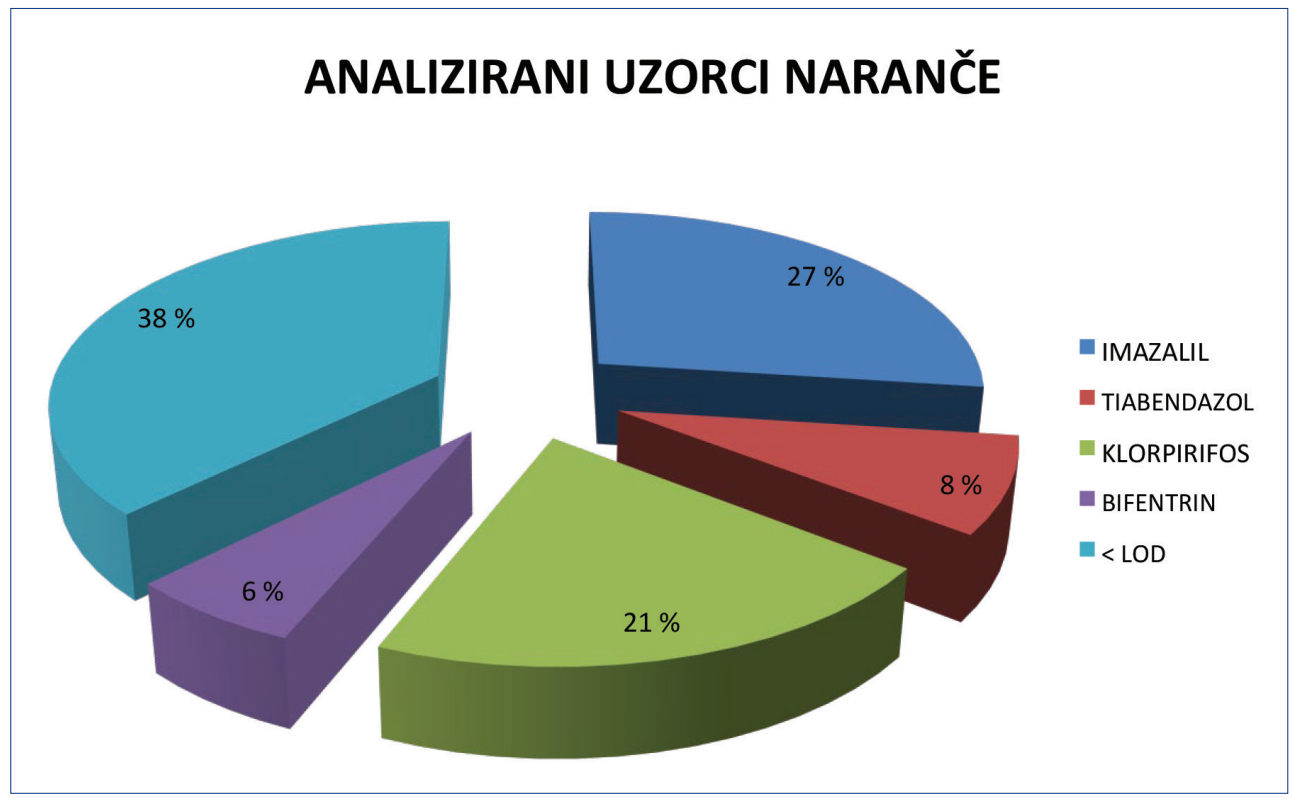

Grafikon 2. Postotak uzoraka u kojima je detektirana aktivna tvar

Na svih jedanaest uzoraka potvrđena je prisutnost aktivne tvari klorpirifosa na plodu (kori naranče) u navedenim količinama. Prisutnost iste tvari na pulpi bilo je manje od granice kvantifikacije te stoga nije dokazan transfer.

\begin{tabular}{|c|c|c|c|}
\hline & & $1 \mathrm{~N} 1 \mathrm{N11}$ & \\
\hline Uzorak & Kora & Pulpa & $\begin{array}{l}\text { Transfer } \\
\text { aktivne tvari }\end{array}$ \\
\hline 1 & $<$ LOQ & I & I \\
\hline 2 & $<\mathrm{LOQ}$ & I & 1 \\
\hline & $<L O Q$ & 1 & 1 \\
\hline
\end{tabular}


Prisutnost aktivne tvari bifentrin dokazana je u tri uzorka, ali ispod granice kvantifikacije te je zbog toga nije bilo moguće izračunati u pulpi kao niti dokazati njezin transfer.

Analize su dakle u analiziranim uzorcima ukazale na prisutnost imazalila koja je iznosila $27 \%$, prisutnost klorpirifosa koja je iznosila $21 \%$, prisutnost bifentrina koja je iznosila $6 \%$ te prisutnost tiabendazola koja je iznosila $8 \%$.

Važno je napomenuti da u $38 \%$ analiziranih uzoraka nije detektirana prisutnost nijedne od 88 aktivnih tvari na koje su uzorci analizirani.

Nadalje, bifentrin je bio potvrđen na tri uzorka, ali je njegova količina na kori bila $<$ LOQ te njegov transfer na pulpu nije bilo moguće odrediti.

Prisutnost klorpirifosa bila je potvrđena u 11 uzoraka, ali je njegov transfer s kore na pulpu bio < LOQ.

Tiabendazol je bio detektiran na četiri uzorka te je dokazan transfer s kore na pulpu na tri uzorka koji je iznosio između $21 \%$ i $25 \%$. Na jednom uzorku nije bilo moguće odrediti transfer jer je detekcija aktivne tvar na pulpi bila $<$ LOQ.

Prisutnost aktivne tvari imazalila bila je potvrđena na 13 uzoraka, dok je na osam uzoraka dokazan transfer $\mathrm{s}$ kore na pulpu te se kretao u rasponu od $22 \%$ do $30 \%$. Na pet uzoraka nije bilo moguće dokazati transfer imazalila jer je njegova količina na pulpi bila < LOQ.

\section{Zaključak}

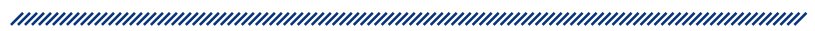

Analize 48 uzoraka pokazale su da na njih 20 nije bilo detektirana prisutnost nijedne od 88 analiziranih aktivnih tvari. Na 28 uzoraka bila je potvrđena prisutnost jedne ili više aktivnih tvari. Transfer je dokazan na 11 uzoraka, od toga osam transfera imazalila i tri transfera tiabendazola. Može se zaključiti da se kao najčešće detektirana tvar izdvojio imazalil, a najčešće tretirane naranče bile su iz Španjolske. Njegova prisutnost može se objasniti činjenicom da je imazalil najčešća aktivna tvar koja se upotrebljava za suzbijanje truljenja ploda prilikom skladištenja i transporta, a budući da je riječ o uzorcima iz uvoza, nije neočekivano da se naranče tretiraju radi dugog transporta i skladištenja. Važno je ista- knuti da na devet od 14 uzoraka iz Hrvatske nije detektiran nijedan od navedenih analiziranih aktivnih spojeva.

lako se postotak dokazanih transfera aktivne tvari s kore na pulpu kretao u rasponu od $20 \%$ do $30 \%$, važno je napomenuti da ni na jednom od 48 analiziranih uzoraka količina detektirane aktivne tvari nije bila iznad MDK-a te kao takva nije predstavljala rizik za zdravlje ljudi. Stoga je zaključna ocjena da su se rezultati dobiveni ovim istraživanjem pokazali više nego zadovoljavajućima za naše tržište.

\section{Referencije}

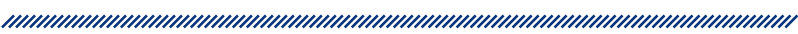

1. http://hr.wikipedia.org/w/index.php?title=Naranča\&pr intable=yes. Dostupno na: https://hr.m.wikipedia.org> wiki>Naranca (pristupljeno 1.6.2020.).

2. ISO 17025 standard.

3. HRN EN 12393:1998.

4. Najviše dopuštene količine aktivnih tvari u uzorcima naranče http://ec.europa.eu 


\section{DISTRIBUTION OF PESTICIDE RESIDUES BETWEEN ORANGE PEEL AND PULP}

1 Ljubica Hrnjkaš

2 Aleksandar Racz

1 Croatian Institute of Public Health, Rockefeller str. 7, Zagreb, Croatia

2 University of Applied Health Sciences, Mlinarska 38, Zagreb, Croatia
Keywords: orange, transfer, pesticides, imazalil, chlorpyrifos, thiabendazole and bifenthrin

\section{Abstract}

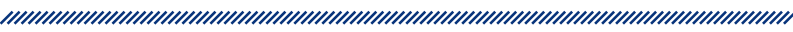

The aim of this paper was to prove the transfer of pesticide residues from the peel to the orange pulp if the presence of the pesticides is proven on the peel. For this purpose, the paper analy zed 48 samples of imported oranges and oranges of domestic origin in which the analyzes were focused on the detection of 88 active substances. The results confirmed the presence of 4 active substances: imazalil, chlorpyrifos, thiabendazole and bifenthrin, where the transfer of active substances was proven on 11 samples, and ranged from $20 \%$ to $30 \%$. 